\title{
Mineral Trioxide Aggregate Apexification in a Nonvital Immature Central Incisor Tooth using an Internal Matrix
}

\author{
${ }^{1}$ Mohit A Bodhwani, ${ }^{2}$ Vanitha U Shenoy, ${ }^{3}$ MV Sumanthini
}

\begin{abstract}
Apexification is a method to induce a calcified barrier in a root with an open apex or the continued apical development of an incomplete root in teeth with necrotic pulp. Mineral trioxide aggregate (MTA) has shown immense potential as an apical plug to induce apexification. It is better than the traditionally used calcium hydroxide as it completes the procedure more quickly and effectively. The following case report stresses on the need of an internal matrix to avoid unwanted extrusion of MTA in the periapical tissues. The internal matrix used in this case report is calcium hydroxide.
\end{abstract}

Keywords: Apexification, Open apex, Mineral trioxide aggregate, Internal matrix, Calcium hydroxide.

How to cite this article: Bodhwani MA, Shenoy VU, Sumanthini MV. Mineral Trioxide Aggregate Apexification in a Nonvital Immature Central Incisor Tooth using an Internal Matrix. J Contemp Dent 2014;4(2):113-117.

Source of support: Nil

Conflict of interest: None

\section{INTRODUCTION}

The ultimate goal in the practice of endodontics is to debride and obturate the canal as efficiently and three dimensionally as possible in an amount of time and appointments that are reasonable to the patient. While most endodontic cases can be managed precisely and comfortably, there is a group of patients that differ from providing routine treatment. They present with incompletely formed apex. When such teeth have lost their vitality during the early period of development, apexogenesis will not be a viable option. This group requires a specially tailored treatment plan, different from the other patients, often times requiring much more than 1 year to complete depending on the degree of apical immaturity. ${ }^{1}$

In the absence of a natural apical constriction, the production of mineralized tissue in the apical region is important to create an apical barrier and allow three-dimensional adaptation of obturating material within the root canal system. Several materials have been used in order to induce

${ }^{1}$ Postgraduate Student, ${ }^{2}$ Professor and Head, ${ }^{3}$ Professor

${ }^{1-3}$ Department of Conservative Dentistry and Endodontics, MGM Dental College and Hospital, Navi Mumbai, Maharashtra, India

Corresponding Author: Mohit A Bodhwani, Postgraduate Student, Department of Conservative Dentistry and Endodontics, MGM Dental College and Hospital, Navi Mumbai Maharashtra, India, Phone: 9819039311, e-mail: mohitbodhwani@gmail.com a hard tissue barrier, such as calcium hydroxide, mineral trioxide aggregate (MTA), biodentine among others. Calcium hydroxide $(\mathrm{CH})$ has been commonly used as an intracanal dressing to induce hard tissue deposition in necrotic teeth with open apices. The $\mathrm{CH}$ is renewed periodically until an apical barrier is formed. The time needed to form an apical barrier is unpredictable, usually ranging from 6 to 18 months and depends on the size of the apical foramen, the presence of infection and the host response. ${ }^{2}$

Mineral trioxide aggregate (ProRoot, Dentsply) is composed of bismuth oxide, tricalcium silicate, dicalcium silicate, calcium dialuminate and calcium sulphate dehydrated, trace elements like iron, nickel, copper and strontium. ${ }^{3}$ Mineral trioxide aggregate has shown potential as a root-end filling material. ${ }^{4}$ Despite its outstanding tissue biocompatibility, MTA has several disadvantages, which include a delayed setting time, poor handling characteristics, unpredictable antibacterial effects and high costs. ${ }^{5}$ Mineral trioxide aggregate is a powder consisting of fine hydrophilic particles that bind in the presence of moisture. Set MTA provides a good seal and excellent marginal adaptation. In vivo studies have confirmed biocompatibility of this material and have shown a hard tissue inductive effect. ${ }^{6}$

In the absence of an apical constriction, extrusion of the filling material may occur which might delay the healing process. Thus, Lemon advocated the use of an internal matrix when the perforation diameter is larger than $1 \mathrm{~mm}$ to avoid extrusion of the sealing material. ${ }^{7}$ Several materials have been recommended to create a matrix, in cases of perforations as well as teeth with incomplete formation of apex which includes $\mathrm{CH}$, hydroxyapatite, resorbable collagen and calcium sulfate. ${ }^{8}$

This article presents the management of an immature tooth by the use of an internal matrix prior to apexification using MTA.

\section{CASE REPORT}

A 19-year-old female patient reported to the Department of Conservative Dentistry and Endodontics, MGM Dental College and Hospital, with a chief complaint of a discolored maxillary right central incisor (11). History revealed that the patient had suffered trauma at the age of 8 years and had received endodontic treatment from a private clinic. Medical history of the patient was noncontributory. 
Clinical examination revealed discolored 11 (Figs 1 and 2), and an access cavity preparation had been performed in the tooth. The tooth tested negative to both electric and cold tests. Radiographic examination revealed an incomplete formation of the root apex with 11 (Fig. 3) and apical radiolucency with maxillary left central and lateral incisors $(21 / 22)$. Periodontal status was fair. Periodontal probing depths were within normal limits and there was no associated mobility.

Under rubber dam isolation, the access preparation was modified and the remaining coronal shell was strengthened using composite resin (Filtek Z350, 3M ESPE). Working length was determined radiographically (Fig. 4) followed by minimal circumferential filing using $\mathrm{H}$-files (Mani, India) and copious irrigation with saline and $5 \%$ sodium hypochlorite (Vishal Co., India).

Dry, sterile $\mathrm{CH}$ powder (Vishal Co., India) mixed with saline to a thick consistency and was placed within the canal for 7 days as an intracanal medicament (Fig. 5).

In the follow-up appointment, $\mathrm{CH}$ intracanal medicament was removed with saline and $\mathrm{H}$-files. The root canal

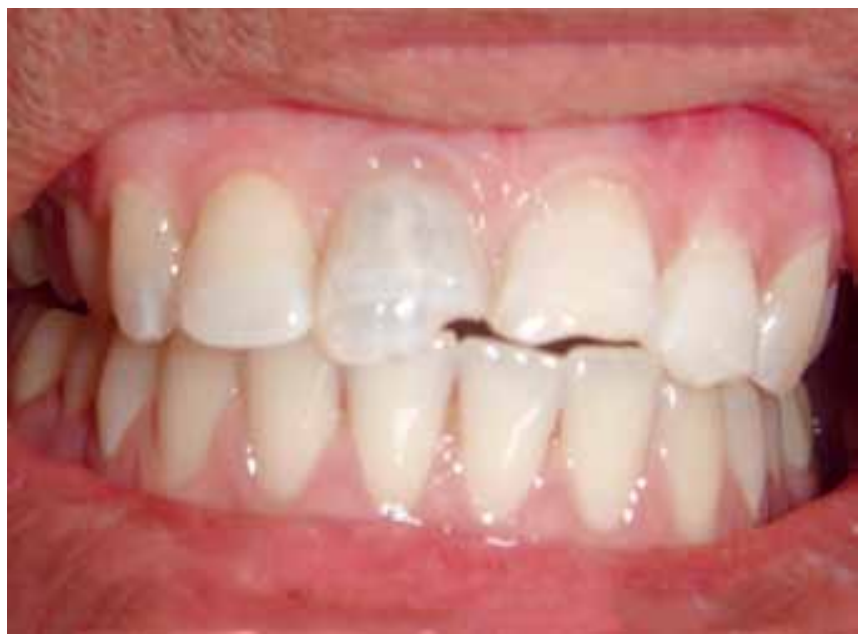

Fig. 1: Preoperative labial view

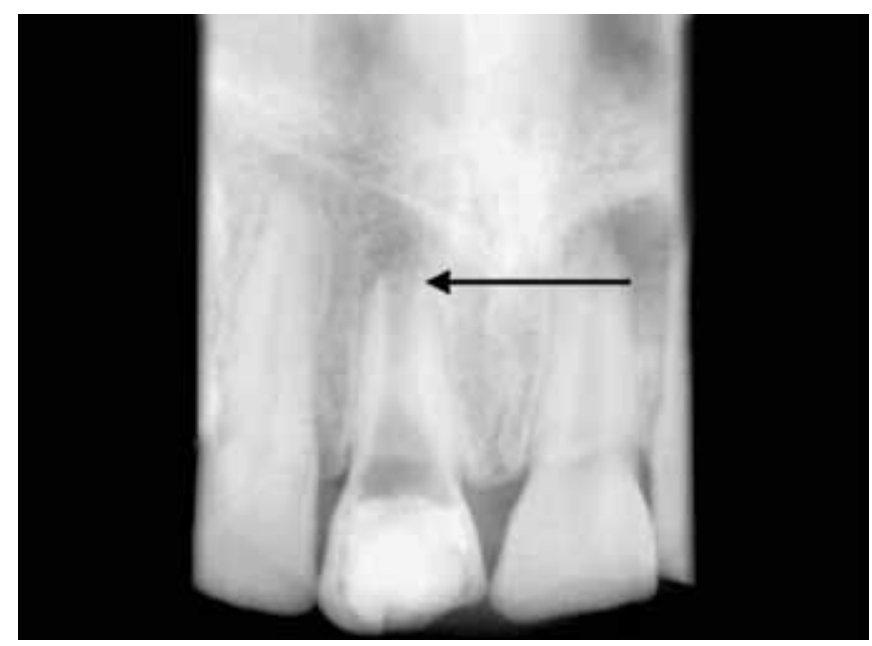

Fig. 3: Intraoral periapical radiograph showing open apex was irrigated with saline and dried using paperpoints. A $1 \mathrm{~mm}$ plug of dry sterile $\mathrm{CH}$ powder was placed at the apex using an amalgam carrier and hand pluggers (Fig. 6), as an internal matrix, which would serve as a barrier against which MTA can be compacted.

Mineral trioxide aggregate (ProRoot MTA, Dentsply), mixed as per manufacturer's instructions and was placed apically upto $5 \mathrm{~mm}$ in two increments which was verified with radiographs (Figs 7A and B).

A moist cotton pellet was placed for 24 hours within the coronal orifice to facilitate setting of MTA.

In the following appointment set of MTA was confirmed with a plugger. Postendodontic treatment included placement of fiber post (Luminex System) and composite core (Filtek Z350, 3M ESPE) (Fig. 8) followed by porcelain fused to metal crown (Fig. 9). Simultaneously, root canal treatment was completed with $21 / 22$.

\section{DISCUSSION}

Traumatic injuries during the root formation stages lead to cessation of the root maturation and leads to the presence

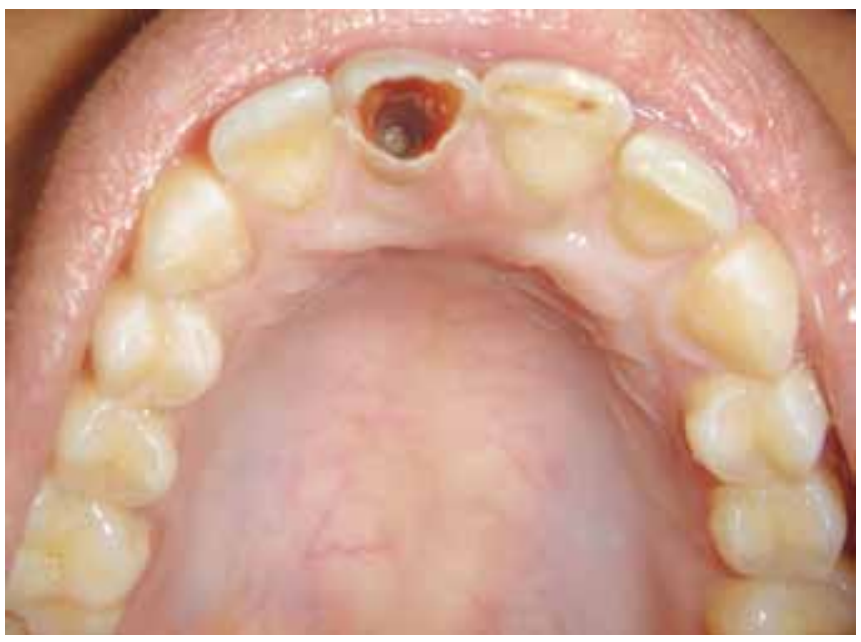

Fig. 2: Preoperative occlusal view

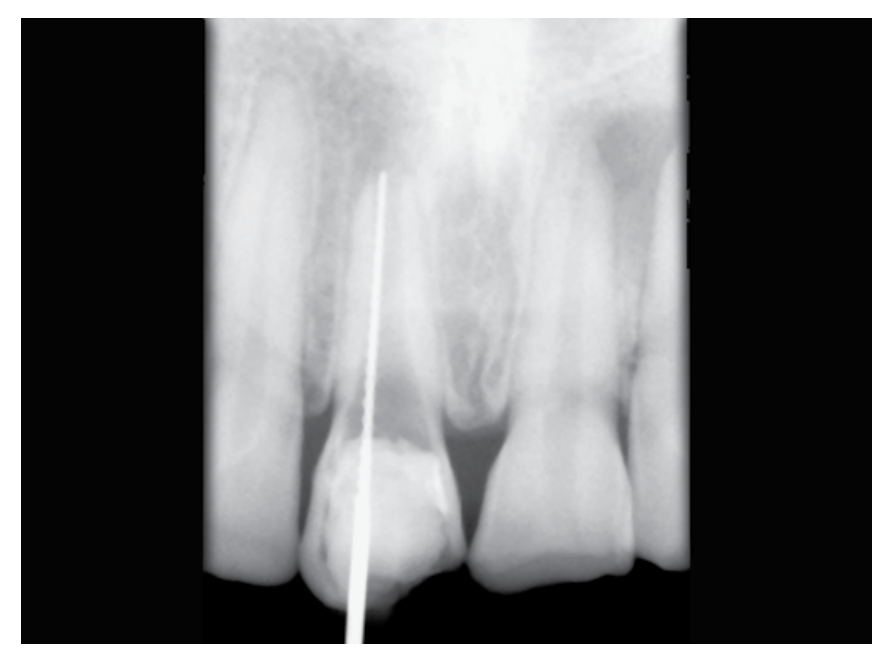

Fig. 4: Intraoral periapical radiograph showing working length 
of an open apex with the tooth involved. Development of the root of an upper central incisor takes place during the 8 th to 10th year of the child's life. Thus, any trauma at this stage leads to incomplete root formation as is seen in the presented case. Root canal treatment at this time is a significant challenge because of the size of the canal, the thin fragile dentin walls and the large open apex. Completion of a root canal filling may be made possible by inducing a hard tissue apical barrier for those teeth which are nonvital. Recent research evidence has demonstrated that the longterm $\mathrm{CH}$ apexification treatment significantly reduces the fracture resistance of the tooth. This is attributed to decreased organic support of dentin matrix leading to disruption of the bond between the collagen fibrils and hydroxyapatite crystals that negatively influence the mechanical properties of dentin. ${ }^{9}$ Despite higher success rate of apical barrier formation using $\mathrm{CH}$ long-term follow-up is essential. Previous studies have described the disadvantages of $\mathrm{CH}$ apexification, such as long-term therapy lasting anywhere between 6 and 36 months, failure to control infection, recurrence of infec-

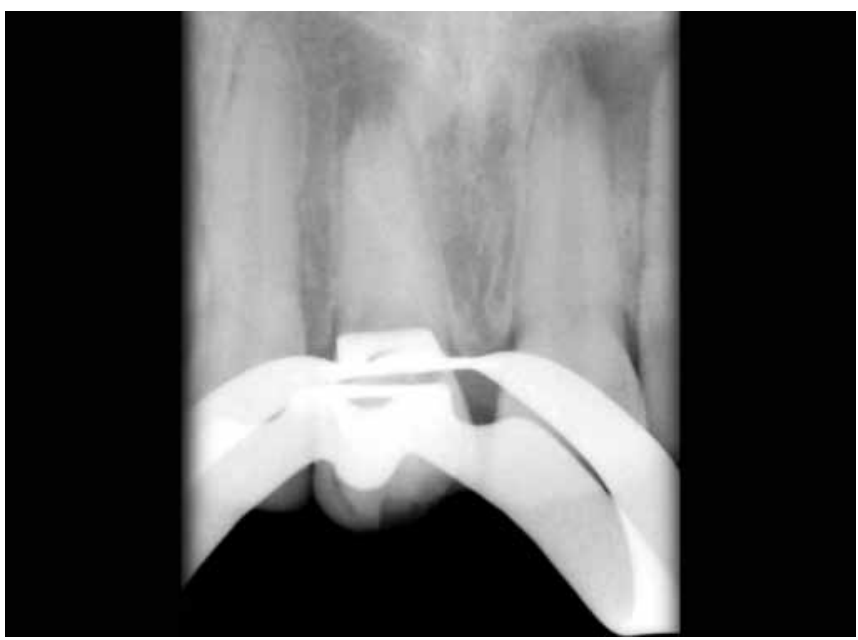

Fig. 5: Intraoral periapical radiograph showing dense calcium hydroxide dressing

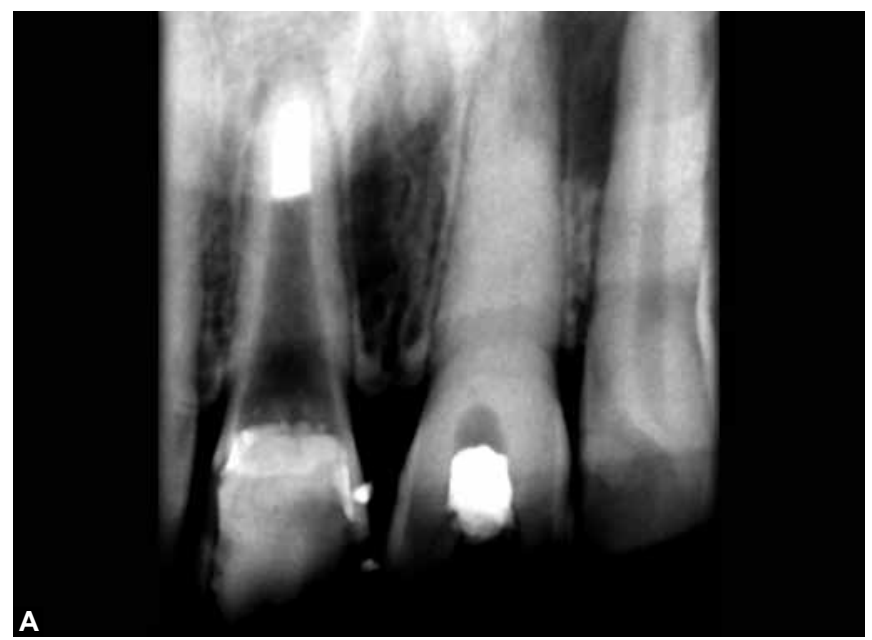

Figs 7A and B: (A) Intraoral periapical radiograph showing 1st increment of MTA, $(B)$ intraoral periapical radiograph showing 2nd increment MTA

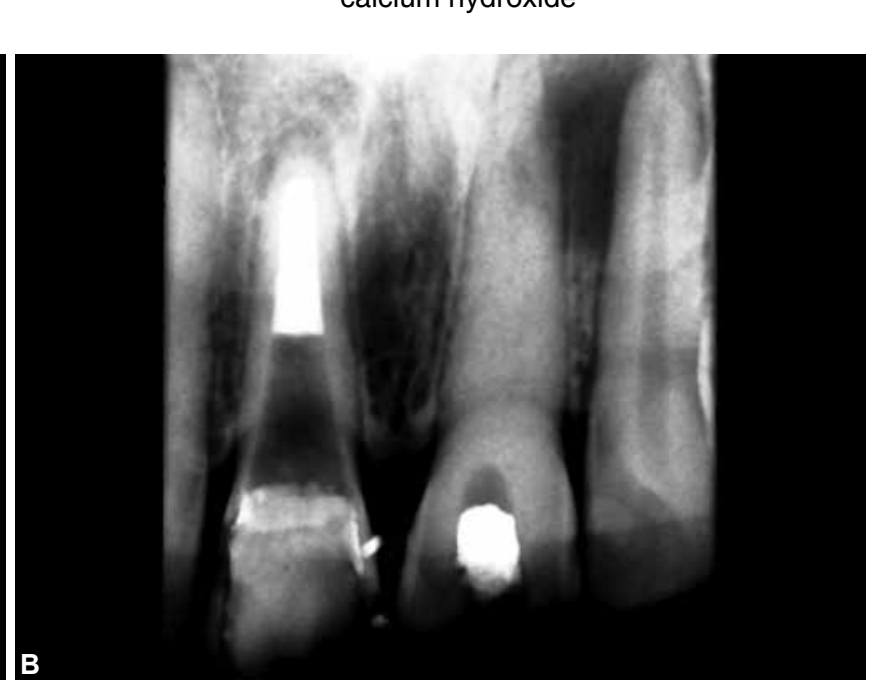

tion due to loss of coronal seal, reduced patient compliance and cervical fracture. ${ }^{10}$ The patient reported here with a weakened coronal tooth structure having a shell of enamel with loss of dentine. The coronal aspect was reinforced with composite resin at the onset of the treatment in order to prevent coronal tooth structure fracture during the subsequent treatment procedures.

A common disadvantage of teeth with open apices is the reduced fracture resistance due to reduction in the amount of presence of root dentin, thus minimum shaping of the root canal was performed. Emphasis was placed on the cleaning and disinfection of the root canal by irrigants and intracanal medicaments.

In the present case, $\mathrm{CH}$ was used for 7 days as an intracanal medicament, since it is known to significantly reduce the endodontic microflora without compromising the fracture resistance of dentin. Calcium hydroxide when placed for not more than 30 days does not cause any deleterious effect on dentin. ${ }^{11}$

Apexification treatment is supposed to create an environment to permit deposition of cementum, bone and periodontal

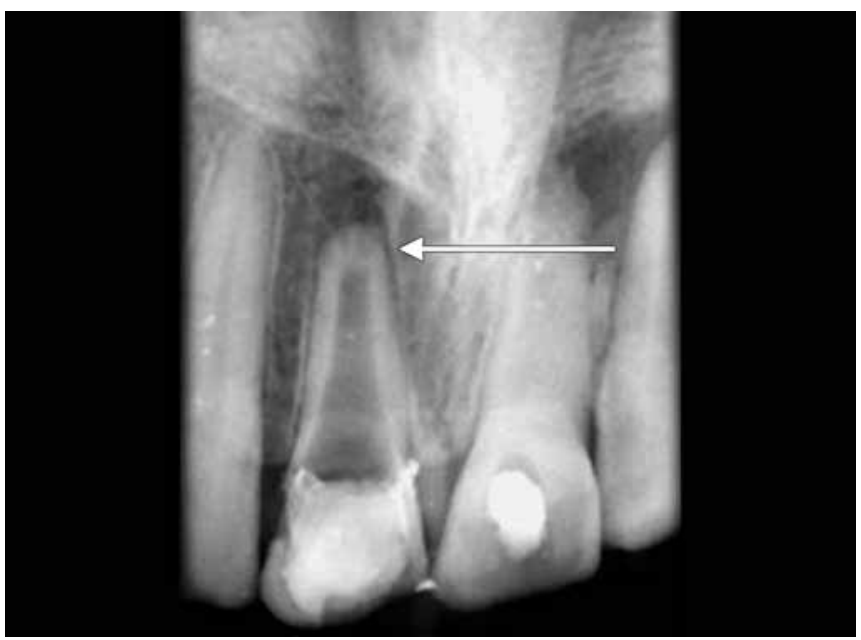

Fig. 6: Intraoral periapical radiograph showing internal matrix of calcium hydroxide 
ligament to continue its function of root development. The goal of this treatment is to obtain an apical barrier to prevent the passage of toxins and bacterial into the periapical tissues from root canal. Technically this barrier is necessary to allow compaction of root filling material. ${ }^{12}$

Mineral trioxide aggregate has shown to be effective in performing the same procedure in a considerably lesser period of time with predictable results when compared to traditional apexification using $\mathrm{CH}$. Mineral trioxide aggregate placement in a wide open apex may result in its extrusion into the periapical area, which may result in the persistence of the inflammatory process, which may complicate or even prevent repair of the tissues. ${ }^{13}$ Thus, the extrusion of MTA into the periapical tissues can be prevented by the use of an internal matrix, which reduces the leakage of the sealing material and allows favorable response of the periodontal tissues. Several materials have been recommended for the fabrication of this matrix, including resorbable collagen, calcium sulphate, $\mathrm{CH}$, hydroxyapatite, tricalcium phosphate and demineralized bone. ${ }^{14}$ Calcium hydroxide, resorbable collagen or calcium sulphate are usually recommended as suitable matrix materials. The advantage of these materials is the possibility of resorption in the bone wound, thus allowing new bone formation.

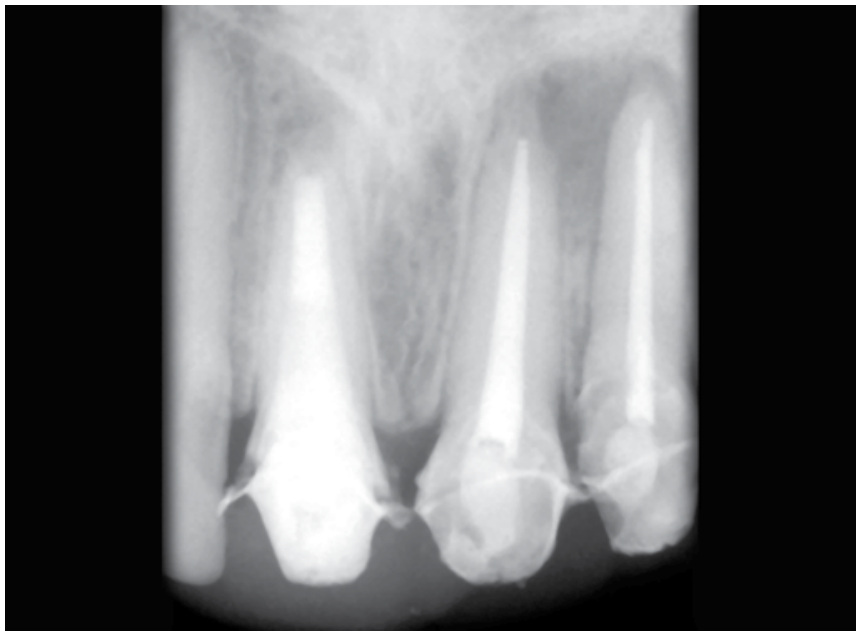

Fig. 8: Intraoral periapical radiograph showing fiber post placement and composite core build up

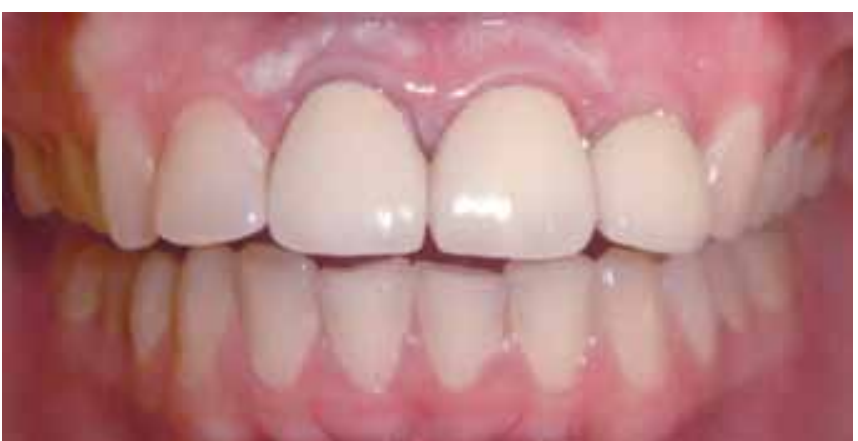

Fig. 9: Postoperative clinical photograph following the placement of full coverage crowns in 11, 21 and 22
Dry calcium hydroxide powder was the material of choice to create the internal matrix, because it is biocompatible with the periapical tissues, resorbable, good handling properties, easily available and cost-effective. ${ }^{15}$ The use of matrix is advisable, since its placement in the area of bone destruction provides a base on which the sealing material especially MTA can be placed and packed onto. Mineral trioxide aggregate when freshly mixed has a soft consistency and may be layered without pressure againt the internal matrix placed. Calcium hydroxide takes about 6 months to resorb.

Five millimeters apical plug of MTA was placed in the presented case. The manufacturer of MTA recommends 3 to $5 \mathrm{~mm}$ thickness of MTA for apexification procedure. Al-Khatani A et al observed that a $5 \mathrm{~mm}$ apical plug completely prevented bacterial leakage. ${ }^{16}$

The production of bone morphogenetic protein-2 (BMP-2) and transforming growth factor beta-1 (TGF $\beta-1$ ) could be two important contributors to the favorable biologic response stimulated by MTA in human periapical tissues. ${ }^{17}$ It has also been shown that the stimulation of interleukin production by MTA may allow for the overgrowth of cementum and facilitate the regeneration of the periodontal ligament and formation of bone. ${ }^{18}$

In order to deliver the necessary dampness for the hardening of the MTA, a wet cellulose swab, moist gauze, moist cotton pellet have been recommended, though moist cotton pledget has a disadvantage of cotton fibers which may stick to the MTA and also risk of bacteria re-entering the cavity through the temporary filling. In the present case, moist cotton pledget was used, but care was taken to see to it, that no fiber extended through the temporary filling.

One visit apexification avoids the possibility of leakage between visits, shortens the treatment time between the patient's first appointment and the final restoration and because a bonded post could be placed immediately within the root canal and the core build up and final restoration can be delivered quickly, the potential for fracture of immature teeth is reduced, all of which makes the one appointment MTA procedure cost-effective.

Mineral trioxide aggregate has two specific phases composed of calcium oxide and calcium phosphate after reaction with water. Thus, MTA has calcium oxide on its surface that could react with tissue fluids to form calcium hydroxide. For this reason, it is believed that MTA actively promotes hard tissue formation rather than being inert or an irritant like most other materials. New cementum may be derived from either the remaining periodontal ligament or it is derived from the ingrowing connective tissue. ${ }^{19}$

While it is recognized that extrusion of MTA via an open apex is not a common mishap during the apexification 
procedure, the extruded material does not negatively affect the healing of the periapical tissues, as supported by follow-up observations of 36 to 54 months. If a complete closure of the root apex is considered the ideal goal to be achieved for the apexification procedure, this goal has been achieved in the present case. However, deliberate overfilling of MTA into the periapical lesion is not advocated in any clinical circumstance. Revascularization procedure, as a further advanced procedure, is highly suggested for this kind of cases to get a biological healing including continuing of root formation without the risk of material extrusion. ${ }^{20}$

\section{CONCLUSION}

Nonvital teeth with immature or open apex can be successfully treated by apexification with MTA and $\mathrm{CH}$ as internal matrix. Though, numerous materials have been suggested for use as an internal apical matrix material, selective cases due to lack of time, cost factor can still be treated using $\mathrm{CH}$ matrix against which MTA can be placed to achieve positive results.

\section{REFERENCES}

1. Mathews BP, Hegde M. Management of nonvital immature teeth. Case reports and reviews. Endodontology 2006;18(1):18-21.

2. Sheehy EC, Roberts GJ. Use of calcium hydroxide for apical barrier formation and healing in nonvital immature permanent teeth: a review. Br Dent J 1997;183(7):241-246.

3. Araceli I, Bucio L, Cruz-Chez E. Phase composition of ProRoot MTA by X-ray diffraction. J Endod 2009;35(6):875-878.

4. Bates CF, Carnes DL, del Rio CE. Longitudinal sealing ability of mineral trioxide aggregate as a root-end filling material. J Endod 1996;22(11):575-578.

5. Parirokh M, Torabinejad M. Mineral trioxide aggregate: a comprehensive literature review-part III: clinical applications, drawbacks, and mechanism of action. J Endod 2010;36(3):400-413.

6. Ribeiro DA, Duarte MA, Matsumoto MA, Marques ME, Salvadori DM. Biocompatibility in vitro tests of mineral trioxide aggregate and regular and white portland cements. J Endod 2005;31(8):605-607.

7. Lemon RR. Nonsurgical repair of perforation defects. Internal matrix concept. Dent Clin North Am 1992;36(2):439-457.

8. Rafter M, Baker M, Alves M, Daniel J, Remeikis N. Evaluation of healing with use of an internal matrix to repair furcation perforations. Int Endod J 2002;35(9):775-783.

9. Andreason JO, Farik B, Munksgaard EC. Long-term calcium hydroxide as a root canal dressing may increase risk of root fracture. Dent Traumatol 2002;18(3):134-137.

10. Torabinejad M, Chivian N. Clinical applications of mineral trioxide aggregate. J Endod 1999;25(3):197-205.

11. Andreasen JO, Munksgaard EC, Bakland LK. Comparison of fracture resistance in root canals of immature sheep teeth after filling with calcium hydroxide or MTA. Dent Trauma 2006;22(3):154-156.

12. Trope M. Treatment of immature teeth with nonvital pulps and apical periodontitis. Endotopic 2007;14(1):51-59.

13. Holland R, Mazuqueli L, Souza V, Murata SS, Dezan E Jr. Influence of the type of vehicle and limit of obturation on apical and periapical tissue response in dogs teeth after root canal filling with mineral trioxide aggregate. J Endod 2007;33(6):693-697.

14. Bargholz C. Perforation repair with mineral trioxide aggregate: a modified matrix concept. Int Endod J 2005;38(1):59-69.

15. Weisenseel JA, Hicks ML, Pelleu GB. Calcium hydroxide as an apical barrier. J Endod 1987;13(1):1-5.

16. Al-Kahtani A, Shostad S, Schifferle R, Bhambhani S. In vitro evaluation of microleakage of an orthograde apical plug of mineral trioxide aggregate in permanent teeth with simulated immature apices. J Endod 2005;31(2):117-119.

17. Guven G, Cehreli ZC, Ural A, Serdar MA, Basak F. Effect of mineral trioxide aggregate cements on transforming growth factor beta 1 and bone morphogenetic protein production by human fibroblasts in vitro. J Endod 2007;33(4):447-450.

18. Cehreli ZC, Sara S, Uysal S, Turgut MD. MTA apical plugs in the treatment of traumatized immature teeth with large periapical lesions. Dent Traumatol 2011;27(1):59-62.

19. Torabinejad M, Pitt Ford T, McKendry D, Abedi H, Miller D, Kariyawasam S. Histological assessment of mineral trioxide aggre-gate as a root end filling in monkeys. Int Endod J 2009;42(5): 408-411.

20. Chang SW, Oh TS, Lee W, Cheung GS, Kim HC. Longterm observation of the mineral trioxide aggregate extrusion into the periapical lesion: a case series. Int J Oral Sci 2013;5(1):54-57. 